\title{
Influence of different weather aspects on breeding performance, food supply and nest-space use in hoopoe offspring
}

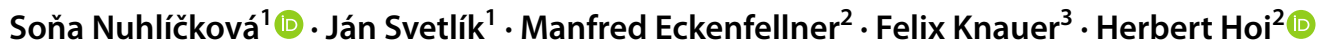

Received: 1 March 2021 / Revised: 3 December 2021 / Accepted: 7 December 2021 / Published online: 29 December 2021

(c) The Author(s) 2021

\begin{abstract}
In this study, we investigated the influence of different weather aspects on breeding performance, food supply and nest-space use in hoopoe offspring (Upupa epops). Camera recordings of 88 nests were used to examine how ambient environmental conditions influence food supply, offspring nest-space use and the trade-off nestlings face regarding the two mainly used locations in the nest. Therefore, we provide a comprehensive analysis involving different factors including weather parameters together with food provisioned to nestlings on different temporal scales to identify the factors having the most influence on nest-space use. We found that different breeding conditions significantly influenced how nestlings used the nest. During excessively humid weather, nestlings spent more time under the entrance hole when small food was delivered. However, nestlings supplied with large prey more often remained hidden in the distant area, despite the adverse weather situation. In all three aspects and temporal scales, our analysis confirmed that prey was the most important factor influencing offspring nest-space use, suggesting a crucial role of large insects for hoopoes. Finally, we found that long-term effects of weather affect overall food provisioned to nestlings and thus offspring behaviour. We provide evidence that parental feeding location and prey size, which are in turn influenced by weather conditions, are the most influential factors for nest-space use. This study expands our knowledge of parent-offspring communication and how environmental factors may lead to differential nest-space use, which may be regarded as the earliest form of habitat preference in birds.
\end{abstract}

\section{Significance statement}

Nests are usually constrained in space but designed to protect offspring from the environment while giving them limited possibilities to express behavioural diversity. This is particularly true for bird nests, where nestlings are usually packed in close contact with one another and without much space for movement, except begging. Here we demonstrate that nest features, such as available nest space together with environmental conditions surrounding a nest, influence nestling strategies and behaviours, including social interactions between nest mates, which further leads to fitness consequences. Our results seem to be of great importance for habitat selection theory in birds, in particular regarding the early development of habitat preferences (imprinting) and use. On the other hand, the result may also have important implications for conservation issues given that nestling behaviour may be used as a determinant of environmental quality.

Keywords Altricial nestlings $\cdot$ Weather conditions $\cdot$ Food supply $\cdot$ Nest-space use $\cdot$ Hoopoe $\cdot$ Upupa epops

\section{Introduction}

Communicated by M. Leonard.

Highlights

Different weather aspects influence the breeding performance and nest-space use of hoopoe offspring

Herbert Hoi

herbert.hoi@vetmeduni.ac.at

Extended author information available on the last page of the article
The ability to choose a proper habitat is an important component of an individual, influencing its life expectancy, performance and fitness (Morris 2011; Uboni et al. 2017; Maresh Nelson et al. 2020). Habitat choice can concern a variety of aspects of life, including the choice of a proper foraging or roosting site, in relation to successful mate attraction or in providing the necessary requirements for reproduction (Gibson et al. 2016; Schwemmer et al. 2016; Evens et al. 
2018; Porter and Akcali 2018). The ability to select the right habitat could be innate, learned or achieved by imitating the choice behaviour of conspecifics, as suggested by the social attraction (Piper 2011; Nielsen et al. 2013; Dixson et al. 2014) or commodity hypothesis (Danchin and Wagner 1997).

Differential habitat use may be important throughout the whole lifetime of an individual, but it can occur even at a very early stage of life. For instance, juvenile fish or anuran larvae actively select a specific habitat during their development (Alford 1986; Armstrong and Nislow 2006). For birds, not much information is available regarding early habitat use, since parent birds usually provide sophisticated rearing environments (nests) for offspring development but limited space to move (Collias and Collias 1985). Thus, for altricial nestlings, the need for differential nest-space use is limited, and whether it is even developed at such an early age is largely unknown.

Weather and predation risk are important environmental factors that may be difficult to forecast, at least in specific landscapes and climatic regions (Lima 2009; Chalfoun and Martin 2010; Rivrud et al. 2010; Reichert et al. 2012; Sauve et al. 2021). Thus, when choosing a habitat, animals have to cope with more or less unpredictable environmental conditions throughout their whole life and adjust their life history traits to changes in the environment (Tökölyi et al. 2012). Weather conditions during the early stages of life can affect offspring both directly and indirectly, e.g. in terms of thermal conditions (Sauve et al. 2021), food availability (Arlettaz et al. 2010, 2017), parental care, e.g. the provisioning effort (Dawson and Bortolotti 2000; Öberg et al. 2015), or changes in parental allocation rules and decisions (Chalfoun and Martin 2010; Ryser et al. 2016). Several studies have been conducted on the effect of seasonal variation in weather conditions on breeding performance (e.g. Tobolka et al. 2015; Wann et al. 2016; Coppes et al. 2021), but less is known about short-term, less predictable changes in the weather, which may require nestlings to respond immediately to, e.g. thermal stress or reduced food availability during rainy periods (Jovani and Tella 2004; Pipoly et al. 2013; França et al. 2020). As a result, offspring may develop strategies to cope with unpredictable situations (Tökölyi et al. 2012), for instance by selecting the most profitable areas in terms of food acquisition, in particular when food is scarce (Budden and Wright 2005). In this context, habitat selection represents a complex decision-making behaviour, where individuals are faced with choices that differ in terms of habitat quality and which can influence fitness outcomes via the costs (e.g. predation risk) or benefits (e.g. food acquisition) of particular habitat use. Consequently, individuals are often assumed to use the habitat where fitness is the highest (Jones 2001; Morris 2003; Piper 2011; Chalfoun and Schmidt 2012).
In a previous study on cavity-nesting European hoopoes (Upupa epops), we demonstrated that when provided with sufficient nest space, nestlings reveal differential nest-space use and even express certain behaviours at specific nest locations (Nuhlíčková et al. 2021). The use of these locations is likely to be affected by parental feeding location, namely whether parents feed inside a nest or from the outside through an entrance hole, but also by nestling age and brood size, which seem to be determinants for nestling nestspace use (Nuhlíčková et al. 2021). For instance, it has been shown that older siblings move more towards the entrance hole, suggesting better locomotor skills with increasing age of hoopoes. Nestlings fed from outside the nest box spent more time under the entrance hole, waiting for parents with food. Furthermore, there is an indication that nestlings face a trade-off regarding nest-space use (Nuhlíčková et al. 2021). If they stay in front of the entrance hole, they receive more food but may suffer higher predation risk and less favourable thermal conditions. On the other hand, if they stay in the dark corner, they may spend more time resting, better protected from predators or avoiding unfavourable ambient thermal conditions but are less likely fed (Wiebe 2001; Wesołowski 2002, 2017; Dawson et al. 2005; Rhodes et al. 2009; Wesołowski and Maziarz 2012; Maziarz and Wesołowski 2013).

Therefore, the main question of this study is whether local environmental (e.g. weather) conditions surrounding a nest influence food provisioned to nestlings, offspring nest-space use and consequently the trade-off nestlings face regarding these two main locations in the nest? Hoopoes are an insectivorous bird species that strongly depend on large prey items and react very sensitively to varying weather conditions. This could be due to changes in prey activity and thus food availability (Arlettaz et al. 2010; Nuhlíčková et al. 2016), altered foraging patterns (Dawson and Bortolotti 2000; Radford et al. 2001) or increased energy demands (Naef-Daenzer 2000; Grieco 2002; Tremblay et al. 2005; Arlettaz et al. 2010), often leading to starvation and the death of subordinate chicks (Martín-Vivaldi et al. 1999; Krištín 2001; Arlettaz et al. 2010). For this reason, we provide a comprehensive analysis involving different weather parameters together with food provisioned to nestlings on different time scales to examine the use of the two most important nest-space locations dedicated to either the food acquisition or resting (trade-off) of hoopoe nestlings (Nuhlíčková et al. 2021).

In the first step, we compare offspring nest-space use in two study years representing different environmental conditions and try to determine which of the following socio-ecological factors may act as important influential parameters for nest-space use: (1) parental feeding strategy (feeding from inside or outside), (2) prey size (in $\mathrm{cm}$ of prey items delivered by parents), (3) feeding rate, including feeding 
visits of both parents, (4) brood size and (5) nestling age. In the second step, we investigate the influence of weather parameters (temperature, humidity and size of prey items delivered) on two different temporal scales: (i) the weather conditions over a longer period - i.e. the nestling period from day of hatching to the day of the behavioural recording (the long-term effect), and (ii) the weather conditions just prior to the observed response, namely the weather on the day of the camera recording up to the moment when the recording was finished (the short-term effect).

We hypothesize that the two study years, which differed in the overall breeding conditions, will be reflected in the distinct parent-offspring behaviour at the nest, changing the importance of the two most frequently used locations and hence the trade-off in their use. We predict that hoopoe nestlings will use the frontal area of the nest box more often in the year with less favourable conditions, for example to be closer to parents with food (Ostreiher 2001; Kölliker and Richner 2004; Dickens et al. 2008) when less energetic food is delivered (see Arlettaz et al. 2010). We assume that parental control over the location where food is delivered will be one of the most important determinants of nest-space use (Nuhlíčková et al. 2021). In this context, offspring may be fed more from the entrance hole even at a younger age, suggesting a change in parental provisioning behaviour (Dawson and Bortolotti 2000; Radford et al. 2001) in the season with less favourable conditions.

Depending on the temporal scale, we also expect that the influence of ambient weather conditions will differ. Weather parameters for example could indirectly but also directly influence, how much time nestlings would need to stay at a specific location. For example, an indirect influence of weather on nest-space use could happen via food availability. Long-term effects of weather e.g. long periods of cold and rainy weather, could affect overall food availability representative for the whole season and hence affect parental food supply. In this context, food availability depends not only the time but also the extent of adverse weather events, which might be important for insect availability, e.g. in terms of fluctuations in prey populations (either seasonal or inter-annual), on prey detectability (partly determined by the prey activity pattern), or on prey accessibility (reviewed in Arlettaz et al. 2010, 2017). For instance, rain and cold periods during emergence and the mating flight, can cause shorter life span of adult scarabeid beetles and a prolonged maturation of the eggs in the body. The older larvae are able to avoid extreme high temperatures and drought by moving to deeper soil (Huiting et al. 2006), making them inaccessible for hoopoes. In this context, adverse weather events can be of different importance. Thus, we expect that weather conditions may operate indirectly, namely through the food supply and for longer temporal scales, shaping the overall parent-offspring behaviour and thus the importance of the two most frequently used locations. As a result, hoopoe nestlings may be forced to spend more time under the entrance hole, in periods with less favourable conditions (Dawson and Bortolotti 2000; Fournier and Arlettaz 2001; Arlettaz et al. 2010; Tagmann-Ioset et al. 2012; Öberg et al. 2015). In line with this, we would not necessarily expect that nestlings immediately respond to each change in weather conditions, especially if the subsequent weather event (situation) does not last for long. For instance, short occasions of rainy weather may not necessarily elicit a nestling response in terms of an adjustment of the position in the nest. Offspring may, despite changing weather, remain either hidden in the corner of the nest box or stay under the entrance hole. Therefore, we predict that short-term weather changes may have a weak impact on nest-space use. However, if weather also operates indirectly, e.g. through changes in food availability, even short weather events could, to some degree, influence nest-space use (prey size). Hence, we predict that differential nest-space use is more likely obvious on a longer temporal scales, i.e. weather conditions predominant and characteristic for the whole nesting or even breeding period.

\section{Material and methods}

\section{General methods}

The study was conducted from May to July 2010 and 2011 in the region of Wagram, Austria $\left(119 \mathrm{~km}^{2}, 230-350 \mathrm{~m}\right.$, $\left.48.45^{\prime}-48.47^{\prime} \mathrm{N} 15.66^{\prime}-15.73^{\prime} \mathrm{E}\right)$. The entire hoopoe population (approximately 100 breeding pairs) bred in nest boxes of size $50 \mathrm{~cm}$ (length) $\times 35 \mathrm{~cm}$ (width) $\times 25 \mathrm{~cm}$ (height) (Nuhlíčková et al. 2016, 2021). The nest-box size was based on the naturally occupied cavities in the upper size range (see Kubík 1960; Krištín 2001; Hudec and Šlastný 2005). The spacious nest sites allowed nestlings to show a variety of behaviours and to distinguish them in relation to nest-space use (for further details, see Nuhlíčková et al. 2021). Nests were inspected twice a week to determine clutch and brood size, hatching date and hence nestling age to determine when they are old enough to start actively exploring the nest. To facilitate this, only broods in the mean age of 8.3-25.7 days were selected from the 88 nests (average age: 16.5 days). Furthermore, at this age offspring also start to engage in sibling competition, including gaping, neck stretching, standing and wing-flapping (see Kilner 2002), and are able to actively move around in the nest box.

In the Wagram vineyards, soil-inhabiting scarabaeid larvae have been determined to be the most dominant prey of hoopoes, making up $73.4 \%$ of identified prey items (Nuhlíčková et al. 2016). The Common Kestrel (Falco tinnunculus) represents one of the most frequent predators in our study population, grabbing hoopoe nestlings through the 
entrance hole or hunting them at or shortly after fledgling. For further specifications about the study area and species, see the detailed description in Krištofík et al. (2013) and Nuhlíčková et al. (2016).

\section{Field study}

Two infrared cameras were used. To determine the nestspace use of nestlings, camera 1 was installed inside the nest box. To collect data on nestling diet and parental feeding ecology, camera 2 was installed outside the nest box. For each nest, $2 \mathrm{~h}$ of recordings were used either in the morning (6:00-9:00 am) or in the afternoon (5:00-8:00 pm), since parents were most active in terms of food provisioning during these periods (Nuhlíčková et al. 2016). The recording time (120 min) was automatically controlled via the software. Altogether, camera recordings were obtained from 88 nests, whereby 40 and 48 nests were obtained in 2010 and 2011, respectively. Tarsus length and weight of nestlings measured at the age of approx. 18-19 days were used as supplementary information to compare chick condition in the two different breeding periods. In total, body measurements from 39 different nests were included in this study (19 and 20 nests were included in 2010 and 2011, respectively, and in total, 84 and 83 chicks were measured with the average \pm SE age of $19.7 \pm 2.6$ and $18.8 \pm 2.12$ days in 2010 and 2011) (see Supplementary material 1). For further specification related to the field study, see Nuhlíčková et al. (2021).

\section{Determination of nest-space use}

Overall nest-space use was previously determined by Nuhlíčková et al. (2021), in which the relative frequency $(\%)$ of nestlings occurring in six same-sized areas $(16.6 \times 17.5 \mathrm{~cm})$ within the overall nest space was observed (Fig. 1). In this study, nestlings seemed to preferentially use specific areas, namely the frontal area $(\mathrm{FH})$ under the entrance hole and the distant area (FC) in the front corner of the cavity (see Fig. 1). Vigorous begging of chicks (e.g. calling, wing-flapping and moving towards the parent (see Kilner 2002), usually starts from the distant (FC) or frontal area $(\mathrm{FH})$ immediately after parental arrival with food. Thus, with the help of recordings from camera 1, nest-space use was determined by stopping the footage for exactly one minute prior to a feeding event (parental arrival with food). At that moment, the position of each nestling was noted. When a bird was standing on the border of two areas, the nestling position was assigned to the area where the larger part of the body was located.

In this study, 6584 observations of nestlings' positions were determined from 88 nests during two successive years (40 and 48 nests with 2174 and 4410 positions in 2010 and 2011, respectively) (see Supplementary

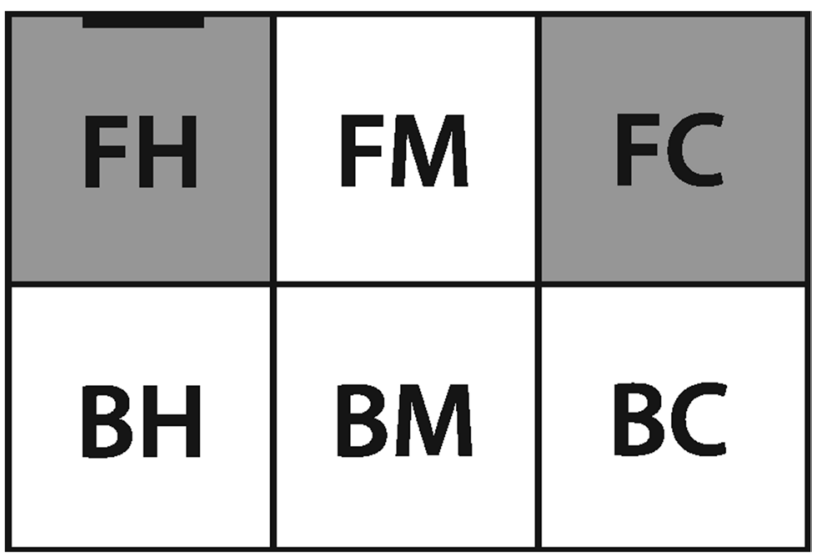

Fig. 1 Diagram of the nest-box interior divided into six same-sized hypothetical areas. The upper side represents the frontal and the lower side the back areas of the nest box. The black bar on the upper side of the FH indicates the location of the entrance hole. The two most frequently used locations included in the analysis are depicted in grey. Abbreviations: $\mathrm{FH}=$ area in front of the entrance hole (frontal area); $\mathrm{FM}=$ front middle area; $\mathrm{FC}=$ front corner area (distant area); $\mathrm{BH}=$ area opposite the hole entrance; $\mathrm{BM}=$ back middle area; $\mathrm{BC}=$ back corner area

material 2). Similar to the previous study, we found that offspring do not use the nest space evenly but show a strong preference for two locations on the grid. Thus, $79.64 \%$ ( $n=5244 / 6584)$ of all positions were recorded in the frontal (FH) and the distant area (FC) of the cavity (see Fig. 1), which were subsequently included in this analysis. The nest-space use was analysed for all nestlings within a nest as one cohort, and individual nestlings were not considered separately.

\section{Determination of socio-ecological conditions}

The socio-ecological conditions in the study area were expressed as (1) prey size delivered to the nestlings and (2) parental provisioning effort expressed as feeding rate, calculated as the number of parental visits with food per hour. For each feeding event, the time of parental arrival with food, prey type and prey size were determined from the recordings of camera 2. Hoopoes are single-prey loaders (they usually bring only one prey item at a time to the nest) (Orians and Pearson 1979), which clearly facilitated prey identification (Fournier and Arlettaz 2001; Arlettaz et al. 2010; Nuhlíčková et al. 2016). Thus, the size of each item was possible to distinguish according to the following categories:

(1) Small prey: the food item was smaller than half of a nestling's beak size (e.g. spiders and flies up to $10 \mathrm{~mm}$ in body length); 
(2) Medium-sized prey: the food item was larger than half of a nestling's beak size (e.g. adult beetles up to $20 \mathrm{~mm}$ in body length);

(3) Large-sized prey: the food item was larger than a nestling's beak size (e.g. larvae of beetles and butterflies, up to $40 \mathrm{~mm}$ in body length) (Nuhlíčková et al. 2016).

To determine the effect of social interactions on the nestlings' nest-space use, nestling age, brood size and parental feeding strategy were included in the analysis, since they are known to influence intra-brood competition (Mock and Parker 1997; Roulin and Dreiss 2012) and hence potentially also nest-space use (see Nuhlíčková et al. 2021). In terms of parental feeding strategies, hoopoe parents enter the nest box and feed their chicks from inside the nest chamber or parents stay outside and feed them through the entrance hole (see Arlettaz et al. 2010; Ryser et al. 2016).

\section{Determination of the weather situation}

Data on weather variability were received by the nearest meteorological station in Langenlois; $\left(48^{\circ} 28^{\circ} \mathrm{N}, 15^{\circ} 41^{\prime} \mathrm{E}\right.$; see www.zamg.at), which is located in the centre of the study area (approx. 3 to $6 \mathrm{~km}$ away from the nearest and farthest nest-box, respectively). To describe the annual differences in breeding conditions, four meteorological parameters were measured during the 2010 and 2011 breeding periods and were used as a supplementary information (see Table 1). A comparison of meteorological data from May to August of both 2010 and 2011 shows that during the two most important months, when the majority of camera recordings were made, May and June 2010 had almost double the rainfall compared to those two months in 2011 (see Table 1; Fig. 2), which was also reflected in higher proportion of overall humidity in 2010 than in 2011.

To determine to what extent nest-space use is affected by weather conditions, daily temperature $\left({ }^{\circ} \mathrm{C}\right)$ and humidity (\%) measurements were among the most important predictors used for insect activity and thus food availability for hoopoes (Arlettaz et al. 2010; Jaworski and Hilszczański 2014). To determine the importance of weather on nestling nest-space use, weather parameters were analysed in two ways: (1) an average value calculated from daily measurements, which included the period (days) from birth when

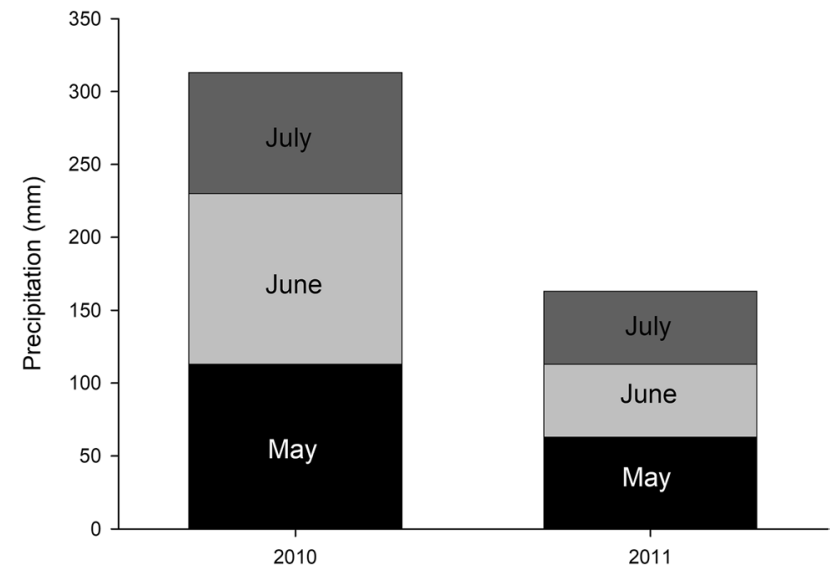

Fig. 2 Monthly precipitation (mm) in two nestling seasons, 2010 and 2011. Separately shown for May (black), June (light grey) and July (dark grey). Source: www.zamg.ac.at

the oldest sibling hatched to the day the camera recording was made (long-term effect), and (2) as the current weather variables measured on the same day when the nest-space use of nestlings was recorded (short-term effect).

\section{Statistical analysis}

It was not possible to record data blind because our study involved focal animals in the field. However to minimize observer bias, blinded methods were used for data analyses.

\section{Annual differences in breeding conditions and nest-space use}

Based on previous results and our own predictions, only the two most frequently used areas (FH and FC) were included in the analyses. A generalized linear model (GLM) was used to compare year differences in (1) feeding rate, (2) prey size, (3) chick residual body mass and (4) average offspring age, when parents started to feed them from outside a cavity. Regarding feeding rate, total feeding rate per hour for both parents was used as the dependent variable, year as the independent factor and nestling number as the covariate. Regarding prey size, average length $(\mathrm{cm})$ of the prey size categories provisioned by both parents per nest and recording $(2 \mathrm{~h})$ was used as the dependent variable, year as the independent
Table 1 The four main meteorological parameters measured in the two breeding periods

\begin{tabular}{|c|c|c|c|c|c|c|c|c|}
\hline \multirow[t]{2}{*}{ Parameter } & \multicolumn{2}{|l|}{ May } & \multicolumn{2}{|l|}{ June } & \multicolumn{2}{|l|}{ July } & \multicolumn{2}{|c|}{ August } \\
\hline & 2010 & 2011 & 2010 & 2011 & 2010 & 2011 & 2010 & 2011 \\
\hline Sunshine duration $[\mathrm{h}]$ & 99 & 291 & 212 & 230 & 249 & 167 & 217 & 255 \\
\hline Temperature $\left[{ }^{\circ} \mathrm{C}\right]$ & 14.6 & 15.3 & 18.8 & 19.7 & 22.1 & 19.5 & 19.0 & 20.9 \\
\hline Humidity [\%] & 76 & 62 & 70 & 63 & 68 & 67 & 75 & 68 \\
\hline Rainfall [mm] & 113 & 63 & 117 & 50 & 83 & 50 & 162 & 31 \\
\hline
\end{tabular}


factor and nestling number as the covariate. To determine the year difference in body condition, residual condition, based on the relationship between body size (tarsus length in $\mathrm{mm})$ and body mass in $\mathrm{g}(r=0.45, F=41.5, p<0.0001$, $d f=1.165)$, was used as the dependent variable and year as an independent factor. To control for brood size, nestling number was used as the covariate. To assess the differences in offspring age between the two study years, (when parents began to be feed from outside the nest box) the average age (in days) of all chicks observed per nest was used as the dependent variable and the year as the independent factor. A multivariate analysis of variance (MANOVA) was used to determine whether there were annual differences in nestspace use, using the time that nestlings spent in the frontal area $(\mathrm{FH})$ under the entrance hole and in the distant area (FC) of the nest box as dependent variables and year and brood size as independent factors. IBM SPSS 20.0 software was used for these statistical analyses.

\section{Importance of socio-ecological conditions}

To determine the importance of socio-ecological conditions on nest-space use, five variables were included as explanatory variables: (1) parental feeding strategy (feeding from inside or outside a nest box), (2) prey size (the size in $\mathrm{cm}$ of prey items delivered by parents), (3) feeding rate per one hour, including feeding visits of both parents, (4) brood size and (5) nestling age. The percentage of the time that nestlings spent in front of the cavity entrance was used as the dependent variable, and the year as the covariate. An information-theoretic approach (Burnham and Anderson 2002) was employed in this study to find the best model for describing the relationship between the five major variables and nest-space use, specifically based on individual discrete choice models. The Akaike information criterion corrected for small sample sizes $\left(\mathrm{AIC}_{\mathrm{c}}\right.$ ) was used to evaluate and compare these different models. To achieve the best model, the methods of model averaging and multi-model inference were applied (Burnham and Anderson 2002). This method allows inference over all the models considered, but it was weighted according to the model as supported by the data. These calculations were conducted in $\mathrm{R}$ using the MuMIn package (Barton 2013). Akaike weights were used to quantify the relative variable importance (RVI) within the model.

\section{Influence of the weather situation}

A generalized linear model (Nelder and Wedderburn 1972) was constructed to explain the variability of nest-space use by chicks in relation to weather conditions, specifically in terms of temperature $\left({ }^{\circ} \mathrm{C}\right)$, humidity $(\%)$ and food quality expressed by the size of prey items delivered (in $\mathrm{cm}$ ). The dependent variable was represented by a matrix with two vectors (together capturing the ratio of time nestlings spent in the frontal area). Such a variable is firmly limited by the interval 0 to 1 (i.e. 0 to $100 \%$ ); thus, we used a binomial regression procedure with logit link. The initial models were compiled as the most complex possible and their terms subsequently tested by analysis of deviance. In the next step, we simplified them by step-by-step removal of their insignificant terms, while respecting the rule of marginality - it is not possible to remove an insignificant term which is part of a significant higher-order interaction. The final model hence represents a further irreducible - minimal adequate model. Based on values of null and residual deviance, we calculated pseudo- $R^{2}$, which captures the proportion of the variation in the dependent variable that is predictable from the independent variable(s). Models were visualized using sigmoid curves with $95 \%$ confidence intervals derived from fitted values $\pm 2 \times \mathrm{SE}$ on the link series, whereas the inverse of the link function was used to map the fitted values and the upper and lower limits of the interval back on to the response series. The modelling and creation of plots were done in the R 3.4.4 environment for statistical computing ( $R$ Core Team 2018).

\section{Results}

\section{Annual differences in breeding conditions and nest-space use}

We found a significant year-on-year difference in (i) average feeding rate (GLM: $F=4.71, p=0.033$; Fig. $3 \mathrm{a}$ ), while controlling for nestling number $(F=0.07, p>0.792)$, (ii) size of prey items provided by the parents (GLM: $F=29.02$, $p<0.0001$; Fig. $3 \mathrm{~b}$ ) and (iii) chick body mass not explained by body size (GLM: $F=14.47, p<0.0001, d f=1$; Fig. $3 c$ ), while controlling for brood size $(F=1.09, p>0.3)$ and average offspring age when parents started to feed them from outside the cavity (GLM: $F=5.045, p=0.031, d f=1.37$; Fig. 3d), when controlling for brood size $(F=1.565$, $p>0.219)$. As a result, feeding rate, prey size and nestling body condition were reduced in the adverse breeding season of 2010 in comparison to the 2011 season, which had more regular conditions (see Fig. 3a-c). In addition, in the adverse season 2010, parents started to feed chicks at a younger average age from outside than in the season with more regular conditions (see Fig. 3d).

Regarding the nest-space use compared in two nestling seasons, we found a significant effect on the use of the two nest positions investigated (MANOVA: Wilks' lambda $=0.89 ; F=4.94 ; d f=2.8 ; p=0.009)$, but no effect of brood size (MANOVA: Wilks' lambda $=0.96 ; F=1.58$; $\mathrm{df}=2.8 ; p>0.21)$. In 2011, nestlings spent less time in the frontal area $(\mathrm{FH})$ but more time in the distant area $(\mathrm{FC})$ of 
Fig. 3 Feeding rate (number of parental visits with food/hour) (a), prey size $(\mathrm{cm})(\mathbf{b})$, nestling condition (residual body mass in $\mathrm{g}$ ) (c) and nestling age (days) when parents started to feed from outside the cavity (through the entrance hole) (d) for year 2010 (grey) and 2011 (open) Averages $\pm \mathrm{SE} /$ nest are given a)

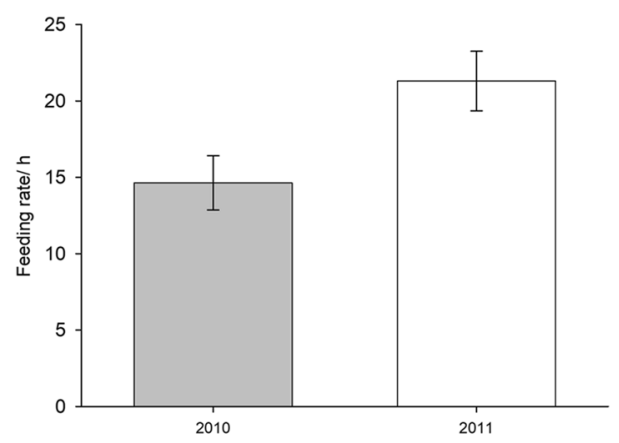

c)

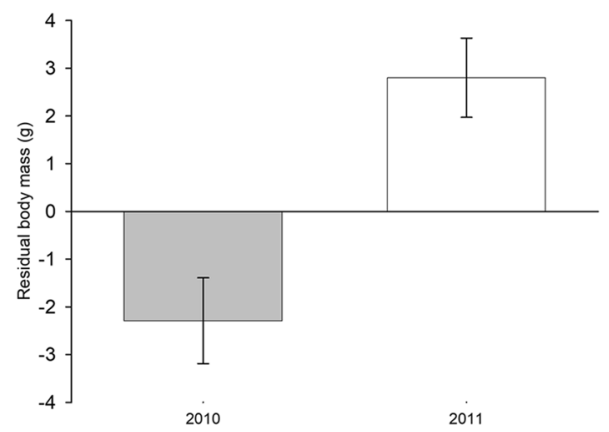

b)

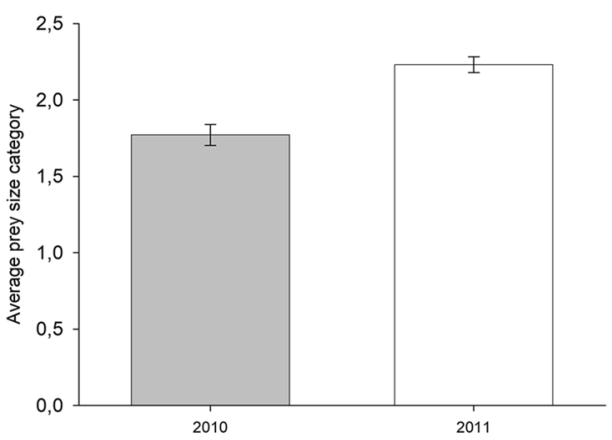

d)

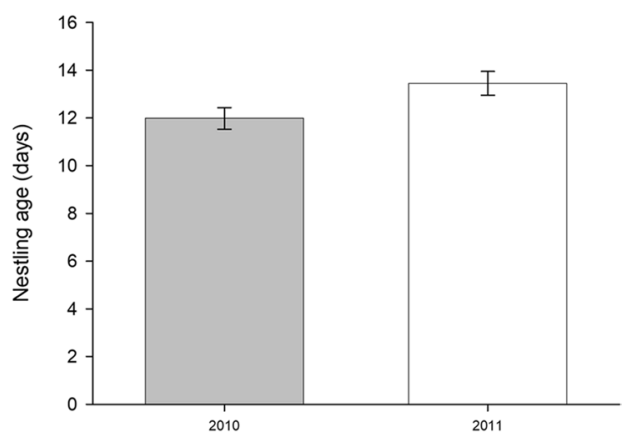

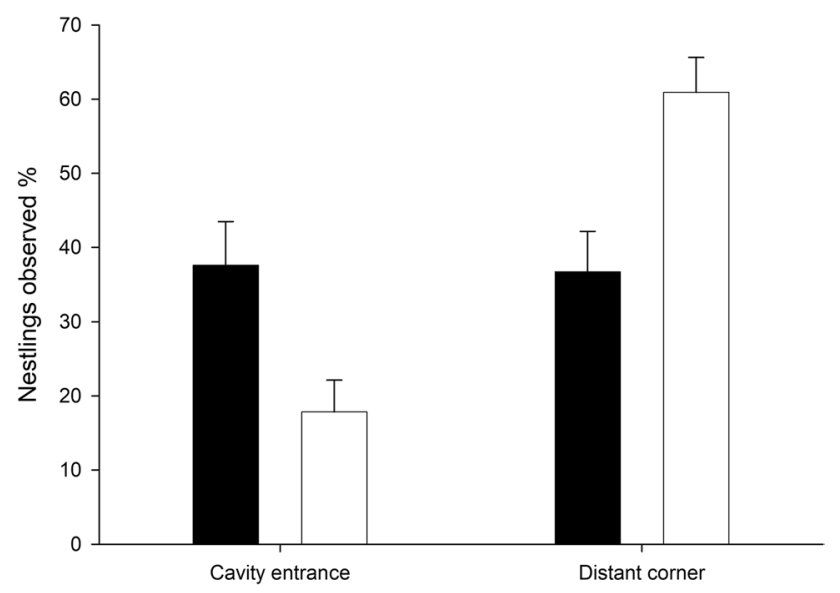

Fig. 4 Percentage observations (\%) in which nestlings were sighted in the frontal area (FH) and in the distant area (FC) of the nest box for the two study years, 2010 (black, $n=40$ nests) and 2011 (open, $n=48$ nests). Averages $\pm \mathrm{SE} /$ nest are given

the nest box than in the adverse 2010 season (Fig. 4). The results further suggest a stronger impact on nest-space use in the distant (FC) $(F=9.78, p=0.002)$ than in the frontal area $(\mathrm{FH})(F=4.33, p=0.04)$ (see Fig. 4$)$.

\section{Importance of socio-ecological conditions}

Analysing the importance of the five parameters to explain nest-space use, but independent of year-to-year differences, an information-theoretic approach revealed the highest relative variable importance (RVI) for parental feeding location. The RVI value was 1 , which suggests parent feeding location to be definitely in the model. The positive parameter estimate indicates that the time nestlings spend in the frontal area $(\mathrm{FH})$ increases with parents starting to feed from outside. According to the RVI value (0.83), prey size is also very likely in the best model to explain the time spent in the frontal area (FH) under the entrance hole. The negative parameter estimates, however, suggests a negative relationship between the size of delivered prey by the parents and time nestlings spent in front of the entrance hole $(\mathrm{FH})$. Finally, the relatively high RVI value for nestling age (0.78) also indicates that nestling age is likely to be in the best model, suggesting that nestling time spent in the frontal area (FH) of the nest box increases with their age. Interestingly, brood size, which could be seen as an indicator of competition over food resources, seems highly unlikely to even be in the model (0.29), and the feeding rate does not seem to be important, given the lower RVI value (0.65), which indicates that the probability being in the model is mere chance (for the overall model output based on particular RVI values, see Table 2 and Supplementary material 3).

\section{Influence of the weather situation: long-term effect}

The model examining the influence of the weather situation on offspring that faced such influence throughout the 
Table 2 Model output specifically based on individual discrete choice models. Given are model-averaged parameter estimates (Estimate), standard error (SE), adjusted standard error (Adjust. SE), z-value, probability $(\mathrm{P})$ and relative variable importance (RVI) for the relationship between the different parameters and the time spent in the frontal area $(\mathrm{FH})$ of the nest box

\begin{tabular}{lrrrrc}
\hline & Estimate & SE & Adjust. SE & $z$ & $P(>|z|)$ \\
\hline Feeding location & 0.4059 & 0.1062 & 0.1076 & 3.773 & $0.000161 * * *$ \\
Prey size & -20.7556 & 7.6239 & 7.7293 & 2.685 & $0.007246 * *$ \\
Nestling age & 15.2393 & 6.8297 & 6.9320 & 2.198 & $0.027921 *$ \\
Feeding rate & 0.5040 & 0.2729 & 0.2761 & 1.825 & 0.067942 \\
Brood size & -1.7614 & 2.6246 & 2.6597 & 0.662 & 0.507812 \\
(Intercept) & 10.1979 & 32.0197 & 32.2448 & 0.316 & 0.751801 \\
\hline
\end{tabular}

Table 3 A generalized linear model, its main factors and their second-order interactions affecting the proportion of time (\%) that hoopoe nestlings spent in the frontal area $(\mathrm{FH})$ of the nest box. Influence of the long-term weather situation

\begin{tabular}{llllc}
\hline & Estimate & Std. error & $z$ & $p$ \\
\hline Intercept & -2.1514 & 1.7668 & -1.22 & 0.223 \\
Humidity & 0.1196 & 0.0067 & 17.97 & $<0.001^{* * *}$ \\
Temperature & -0.2163 & 0.0864 & -2.51 & $0.012^{*}$ \\
Average prey size & -5.2575 & 0.8956 & -5.87 & $<0.001 * * *$ \\
$\begin{array}{l}\text { Tempera- } \\
\text { ture } \times \text { average }\end{array}$ & 0.2250 & 0.0480 & 4.69 & $<0.001^{* * *}$ \\
prey size & & & & \\
\hline
\end{tabular}

Null deviance $=3731.6 ; \quad$ residual deviance $=2572.9 ; \quad$ pseudo $R^{2}=0.311$

whole nesting period, explains $31.1 \%$ of the nest-space use variability (see Table 3 ). When small prey was delivered, the model exhibits a positive relationship between humidity $(\%)$, temperature $\left({ }^{\circ} \mathrm{C}\right)$ and the time nestlings spent in the frontal area $(\mathrm{FH})$ of the nest box. This pattern was also positively related to an ambient temperature of approximately 20 ${ }^{\circ} \mathrm{C}$. Nestlings spent more than half of their time under the entrance hole (FH) when humidity was excessively high at the times when small prey was delivered (Fig. 5). However, the model suggests a completely different pattern when large prey was supplied. At lower to moderate temperatures $(\sim 10$ ${ }^{\circ} \mathrm{C}$ and $\sim 15$, respectively), we found only a slightly positive relationship between humidity (\%) and the time hoopoes spent under the entrance hole (FH). Despite increasing humidity outside the cavity, hoopoes supplied with large prey still spent the majority of their time hidden in the distant corner (FC) of the cavity. Hoopoes tended to move more often towards the entrance hole (FH) only when the ambient temperature was higher $\left(\sim 20^{\circ} \mathrm{C}\right)$.

\section{Influence of the current weather situation: short-term effect}

Examining the immediate response of nestlings in relation to the current weather situation, the model exhibits only a very weak relationship between humidity (\%), temperature $\left({ }^{\circ} \mathrm{C}\right)$ and the time nestlings spent in the frontal area $(\mathrm{FH})$ of the nest box, as less than $1 \%$ of the variability was explained (see Table 4). However, examining the effect of the current weather situation in combination with prey size, the
Fig. 5 Visualization of a generalized linear model which captures the influence of weather conditions (temperature, humidity, size of prey items delivered) on the proportion of time hoopoe nestlings spent in the frontal area $(\mathrm{FH})$ of the nest box. Influence of the long-term weather situation
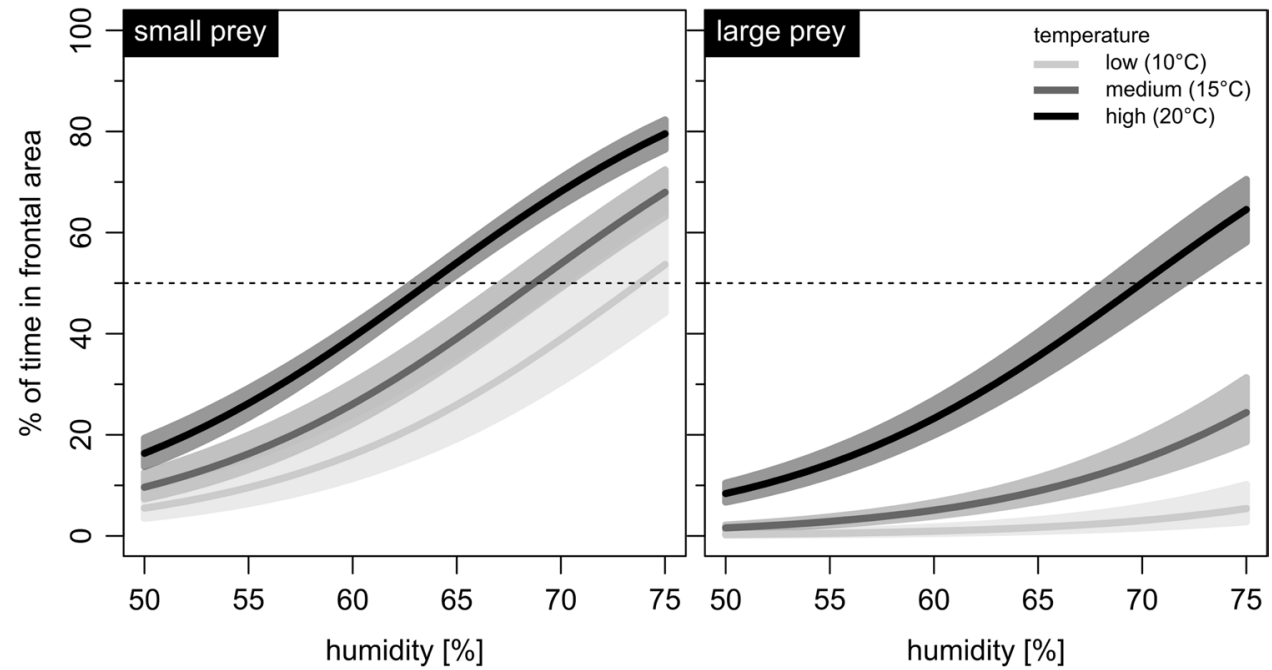
Table 4 A generalized linear model, its main factors and their second-order interactions affecting the proportion of time (\%) that hoopoe nestlings spent in the frontal area $(\mathrm{FH})$ of the nest box. Influence of the current weather situation

\begin{tabular}{lllrc}
\hline & Estimate & Std. error & \multicolumn{1}{l}{$p$} \\
\hline Intercept & 17.5459 & 1.2349 & 14.21 & $<0.001^{* * *}$ \\
Humidity & $-0,0089$ & 0.0030 & -3.01 & $0.003^{* *}$ \\
Temperature & -0.7312 & 0.0619 & -11.80 & $<0.001^{* * *}$ \\
average prey size & -9.9386 & 0.6840 & -14.53 & $<0.001^{* * *}$ \\
$\begin{array}{l}\text { temperature } \times \text { aver- } \\
\text { age prey size }\end{array}$ & 0.4144 & 0.0345 & 12.00 & $<0.001^{* * *}$ \\
\hline
\end{tabular}

Null deviance $=3731.6$; $\quad$ residual deviance $=2895.3$; pseudo $R^{2}=0.224$

model explains $22.4 \%$ of the variability. The strong effect of prey size (Table 4) was reflected in the negative relationship between prey size and the time nestlings spent in the frontal area $(\mathrm{FH})$ of the nest box. When small food was delivered, hoopoes spent the majority of their time under the entrance hole (see Fig. 6). In contrast, when large food was delivered, nestlings spent most of their time in the distant corner of the nest box (see Fig. 6). We found that most of the variability was explained exclusively by prey size and the current weather conditions had almost no effect on nest-space use.

\section{Discussion}

Our results suggest differential habitat use in hoopoes already at a very early stage of life (Nuhličková et al. 2021). In contrast to other taxa (Alford 1986; Armstrong and Nislow 2006), not much information is available on the possibility of early habitat use in birds. Given that parents provide nests which are specifically designed to meet their offspring's needs during their early development and, on the other hand, offspring mobility is usually restricted due to space constraints (Collias and Collias 1985), early habitat use is unlikely to play a significant role. In this context, hoopoes are slightly different, because hoopoe parents do not build nests; they rather search for more or less suitable cavities for raising their offspring (Kubík 1960; Krištín 2001; Hudec and Šlastný 2005). More importantly, we can show that local environmental (e.g. weather) conditions surrounding the nest influence offspring nest-space use. Specifically, two important environmental factors, weather and predation risk (Lima 2009; Chalfoun and Martin 2010; Rivrud et al. 2010; Reichert et al. 2012; Sauve et al. 2021), seem to affect the trade-off nestlings face when choosing between the two preferred localities in the nest. Given the relatively long developmental period of hoopoe nestlings (Krištín 2001; Hudec and Štastný 2005) and the fact that they are still immature and clumsy when the recordings were made, it is surprising to observe nestlings actively responding to environmental changes with differential nest-space use. So, the question arises whether differential habitat use of nestlings is an independent decision and innate (Nielsen et al. 2013; Dixson et al. 2014) or simply driven by physiological needs, e.g. nestlings following the state of hunger (Dickens et al. 2008; Marques et al. 2011) or thermal requirements (Gilbert et al. 2010). When provided with sufficient space, nestlings differentially used their nest space, namely they show a preference for two locations. To receive food, nestlings apparently prefer to move towards the entrance hole to await the arriving parent, a behaviour that has also been observed in other bird species (e.g. Ostreiher 2001; Kölliker and Richner 2004; Dickens et al. 2008). On the other hand, the distant corner of the cavity was used for other behaviours, especially those related to resting or huddling activities (Nuhlíčková et al. 2021), suggesting that this is a site safer from predators (Wesołowski and Maziarz 2012; Wesołowski 2017) or a more stable site regarding thermal
Fig. 6 Visualization of a generalized linear model which captures the influence of weather conditions (temperature, humidity, size of prey items delivered) on the proportion of time hoopoe nestlings spent in the nest frontal area $(\mathrm{FH})$. Influence of the current weather situation

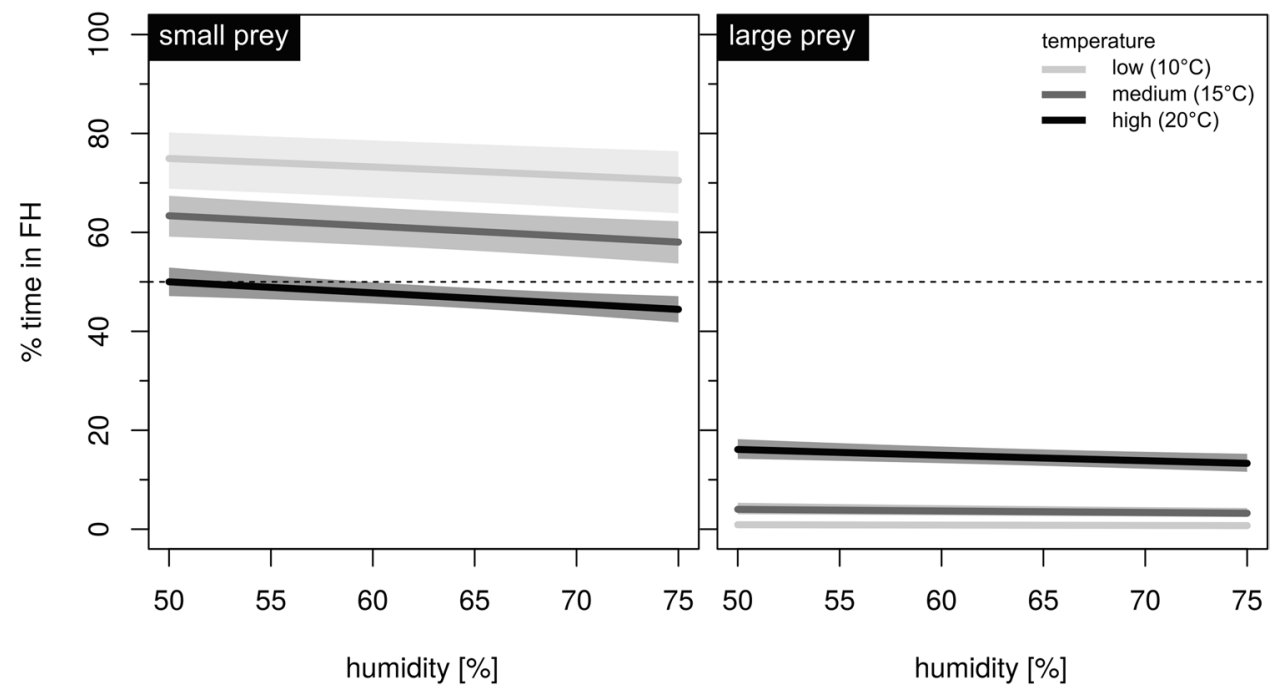


conditions (Amat-Valero et al. 2014; Larson et al. 2015). Thus, if possible, nestlings appear to actively prospect different nest areas for different purposes. This suggests that nestlings are already able to follow some, probably innate rules when selecting their whereabouts.

Beside the importance of environmental conditions, we could also confirm the role of parental feeding strategy as already demonstrated in an earlier study (Nuhlíčková et al. 2021). Based on the high relative variable importance (RVI) value derived using the information-theoretic approach, parental feeding strategy is also in this study the most important determinant for explaining nest-space use. Similarly to Nuhlíčková et al. (2021), we could show that when parents feed from outside, nestlings spend more of their time under the entrance hole compared to the resting patch in the distant corner of the cavity (Nuhlíčková et al. 2021). This indicates the ability of nestlings to predict parental arrival through the entrance hole, given that the entrance hole represents the only access of parents to feed offspring. The predictability of the feeding location further means that hoopoe nestlings are forced to beg from this patch to successfully receive food of their arriving parents. These results are also in accordance with previous studies on other bird species (Bonabeau et al. 1998; Parker et al. 2002; Royle et al. 2002; Kölliker and Richner 2004; Budden and Wright 2005; Porkert and Špinka 2006). However, when comparing the parental feeding strategy in relation to variation in breeding conditions, namely the two different nestling seasons, we also found that during the adverse season parents started to feed their chicks already in an earlier age from outside the nest box compared to the season with more regular conditions. Changing the feeding location from inside the cavity to the entrance hole may indicate a parental strategy to avoid time-consuming decision-making on which offspring to feed at any given feeding event (see Tanner et al. 2007; Ryser et al. 2016). In this context, parents may increase their search time at the cost of time they spend with their offspring, which may be especially beneficial when food is restricted (Naef-Daenzer 2000; Grieco 2002; Tremblay et al. 2005). This further implies, that when the need for investment in gathering food is increased (Grieco 2002), e.g. when food availability is low (Arlettaz et al. 2010; Öberg et al. 2015), hoopoe parents started feed from outside earlier, with the consequences that only chicks in good condition may manage to get enough food and to fledge (Ryser et al. 2016). Our results thus indicate that the choice of the feeding location as well as the timing of the switch between them is under parental control (Nuhlíčková et al. 2021) and, furthermore, is influenced by food availability, e.g. reflected by the different conditions of the two study years.

Given the importance of parents to determine the feeding location and consequently also nestling nest-space use, the question of whether nestling have any independent decision options arises. One parameter identified in this context seems to be prey size, which could directly influence nestling condition (e.g. their state of hunger) and hence affect their nest-space use independent of parental control. The high relative variable importance (RVI) suggests prey size to play a role for nest-space use. The negative parameter estimate in fact implies that the time in front of the entrance hole decreases with increasing prey size. This indicates that prey size and not feeding rate is better reflecting foraging conditions during a breeding season. Thus, when examining the role of ambient weather on nestling nest-space use, prey size has to be taken into account.

Our results from examining weather parameters together with food delivered to offspring indicate that prey size was the most important factor influencing offspring nest-space use, suggesting a crucial role of large insects for hoopoe nestlings (Martín-Vivaldi et al. 1999; Fournier and Arlettaz 2001; Arlettaz et al. 2010), which was supported by both models applied in this study. When parents fed with smaller prey, nestlings spent more time under the entrance hole, but when supplied with large prey, they remained hidden in the distant area of the cavity and started to beg from this patch. These results were additionally supported by comparing the overall breeding situation in two study years. Smaller prey, lower feeding rates, parental provisioning done almost exclusively through the entrance hole and lower chick body mass were found in the adverse year of 2010. Further support is provided by the negative effect of high humidity or rainy weather on food availability, which has been shown to be important for (i) offspring survival (Jovani and Tella 2004; Goławski 2006; Geiser et al. 2008; Arlettaz et al. 2010; Öberg et al. 2015), (ii) parental care in relation to a change of food allocation rules (Caro et al. 2016; Ryser et al. 2016), (iii) provisioning effort (Davis et al. 1999; Radford et al. 2001; Hoset et al. 2004) and finally (iv) offspring response in terms of scramble competition to occupy the most promising areas in front of arriving parents (Ostreiher 2001; Kölliker and Richner 2004; Budden and Wright 2005; Tanner et al. 2007).

Identifying parental feeding strategy and prey size as the most important determinants of nest-space use also raises questions about how much prey supplied to hoopoe chicks depends on weather conditions. Weather conditions are in general very important for species relying on poikilothermic insects, which reduce their overall activity under adverse weather conditions and thereby becoming unavailable to predators (Arlettaz et al. 2010, 2017). The importance of weather for insect availability may be particularly complex in hoopoes, with regard to the timing and extent of adverse weather events (de Zwaan et al. 2020; Sauve et al. 2021). We found that the effects of weather parameters were stronger on the long-term temporal scales. If the weather was humid for a longer period, our results indicate that nestlings were 
provided with smaller prey and spent more time under the entrance hole. Depending to a great extent on soil insects (Fournier and Arlettaz 2001; Tagmann-Ioset et al. 2012; Nuhlíčková et al. 2016), hoopoes may have difficulties reaching their prey, even with their long-curved bills (Krištín 2001). This also indicates that adverse weather conditions operating over a longer period may result in an overall decline of the most profitable prey, namely large scarabaeid larvae (Nuhlíčková et al. 2016). In this context, adverse weather events can be of different importance, which in turn influence parent-offspring behaviour in the nest. Our results indicate that hoopoe parents switch to other prey types, such as large larvae, as already shown in Fournier and Arlettaz (2001) and Arlettaz et al. (2010). Thus, these results suggest that excessively humid weather operating on longer temporal scales indirectly affects food provisioned to nestlings and subsequently parental provisioning behaviour (Geiser et al. 2008; Arlettaz et al. 2010; Caro et al. 2016) and offspring response, for instance in terms of competitive positioning (Kölliker and Richner 2004; Budden and Wright 2005; Tanner et al. 2007). Thus, under scrambled competition to be closer to the feeding parents, nestlings attempt to occupy the most promising locations, which is the frontal area of the nest box.

On the other hand, if short-term weather parameters operate directly on offspring behaviour, our model showed that the current weather conditions had almost no effect on nest-space use. This could be partly due to the fact that in our population nestlings develop in nest boxes and therefore might be less exposed to ambient weather. This may consequently mean that nest box conditions may moderate short-term weather effects on offspring nest-space use and the influence of ambient weather conditions likely depends on the temporal scale. The shorter a weather event, the less likely nestlings may respond with adjusting the nest position. However, by including also food size into the model, we found that also short weather events may elicit a nestling response; nevertheless, in this case the effects seem to be weaker. Thus, it is actually not weather but food availability and food delivered to nestlings, which has the more profound impact on nestling behaviour. This backs up other studies suggesting that prey size is an important determinant of food availability and a major driving force influencing the breeding success of insectivorous bird species relying on large prey (Martín-Vivaldi et al. 1999; Fournier and Arlettaz 2001; Arlettaz et al. 2010, 2017).

In conclusion, our results show that the way nestlings make use of their post-natal environment is not trivial. Further research would be necessary to better understand the role of the interactions among nestlings in relation to nest-space use. Given the hatching asynchrony in hoopoe broods (Hildebrandt and Schaub 2018), it would be interesting to determine individual variation in nest-space use in relation to body size asymmetry and age differences. Furthermore, it would be interesting to consider the role of parental control and sibling competition on nest-space use. For instance, conditional aspects like state of hunger or competitive abilities could be crucial to occupy the best position already before parents arrive with food.

Taken together, nest features, such as available nest space, together with ecological conditions surrounding the nest, influence nestling strategies and provide evidence for an ability in habitat selection, which may even result in fitness consequences. Due to different foraging conditions in the two study years, we found that hoopoe offspring differ in the use of the two most important areas in the nest. To explain nest-space use, parental feeding strategy and prey size, which are in turn influenced by weather conditions, are the most influential factors for nest-space use. This indicates on the one hand parental control over food allocation (Davis et al. 1999; Forbes 2007; Roulin and Dreiss 2012; Ryser et al. 2016; Smith et al. 2017) and on the other hand the crucial role of prey size being sensitive to weather conditions for insectivorous birds (Arlettaz et al. 2010). Thus, parental feeding behaviour, together with decision-making processes of altricial nestlings, may explain the post-natal nest-space use of cavity-nesting birds. Therefore, this study expands our knowledge on parent-offspring interactions and how environmental factors may lead to differential nest-space use, which might be regarded as the earliest form of habitat preferences in birds known in habitat selection theory.

Supplementary Information The online version contains supplementary material available at https://doi.org/10.1007/s00265-021-03117-x.

Acknowledgements We would like to thank the two reviewers and the associate editor Marty Leonhard for their very constructive comments and effort to improve the quality of this study. Furthermore, we would like to thank Renate Hengsberger for revising earlier drafts, preparing the final draft and helping during the entire submission process. We are also grateful to David McLean for the language improvements. Finally, we would like to thank the National Scholarship Programme of the Slovak Republic for financial support of this study.

Author contribution Conceived and designed the experiments: HH, SN, ME, JS

Performed the experiments: SN, HH, ME, JS

Analysed the data: FK, HH, SN

Wrote the manuscript: $\mathrm{SN}, \mathrm{HH}$

Originally formulated the idea: $\mathrm{HH}, \mathrm{SN}, \mathrm{FK}$

Developed the methodology: SN, HH, ME, JS

Conducted the fieldwork: SN, HH, ME, JS

Collaborated on the imaging analysis: SN, JS

Funding Open access funding provided by University of Veterinary Medicine Vienna. This research was supported by the National Scholarship Programme of the Slovak Republic.

Data availability All data generated or analysed during this study are included in this published article and its supplementary information files. 
Code availability Not applicable

\section{Declarations}

Ethics approval Our research adhered to the requirements of the Austrian welfare law, and the necessary ethical approval and licences were obtained under the institutional guidelines of the Austrian Academy of Sciences. Since this is not an animal experiment in a strict sense, no license number was allocated.

Consent for publication All the authors have approved the submitted version and have agreed to be personally accountable for their own contributions and regarding questions related to the accuracy or integrity of any part of the work

Competing interests statement We declare that we have no competing interests.

Open Access This article is licensed under a Creative Commons Attribution 4.0 International License, which permits use, sharing, adaptation, distribution and reproduction in any medium or format, as long as you give appropriate credit to the original author(s) and the source, provide a link to the Creative Commons licence, and indicate if changes were made. The images or other third party material in this article are included in the article's Creative Commons licence, unless indicated otherwise in a credit line to the material. If material is not included in the article's Creative Commons licence and your intended use is not permitted by statutory regulation or exceeds the permitted use, you will need to obtain permission directly from the copyright holder. To view a copy of this licence, visit http://creativecommons.org/licenses/by/4.0/.

\section{References}

Alford RA (1986) Habitat use and positional behavior of anuran larvae in a Northern Florida temporary pond. Copeia 1986:408-423. https://doi.org/10.2307/1444999

Amat-Valero M, Calero-Torralbo MA, Václav R, Valera F (2014) Cavity types and microclimate: implications for ecological, evolutionary, and conservation studies. Int J Biometeorol 58:1983-1994. https://doi.org/10.1007/s00484-014-0801-0

Arlettaz R, Christe P, Schaub M (2017) Food availability as a major driver in the evolution of life-history strategies of sibling species. Ecol Evol 7:4163-4172. https://doi.org/10.1002/ece3.2909

Arlettaz R, Schaad M, Reichlin TS, Schaub M (2010) Impact of weather and climate variation on Hoopoe reproductive ecology and population growth. J Ornithol 151:889-899. https://doi.org/ 10.1007/s10336-010-0527-7

Armstrong JD, Nislow KH (2006) Critical habitat during the transition from maternal provisioning in freshwater fish, with emphasis on Atlantic salmon (Salmo salar) and brown trout (Salmo trutta). J Zool 269:403-413. https://doi.org/10.1111/j.1469-7998.2006. 00157.x

Barton K (2013) MuMIn: multi-model inference (R package version 1.9.5), http://CRAN.R-project.org/package $=$ MuMIn

Bonabeau E, Deneubourg JL, Theraulaz G (1998) Within-brood competition and the optimal partitioning of parental investment. Am Nat 152:419-427. https://doi.org/10.1086/286179

Budden AE, Wright J (2005) Learning during competitive positioning in the nest: do nestlings use ideal free "foraging" tactics? Behav Ecol Sociobiol 58:227-236. https://doi.org/10.1007/ s00265-005-0940-8
Burnham KP and Anderson DR (2002) Model selection and multimodel inference. A practical information-theoretic approach, vol. 2, 2nd edn. Springer, New York

Caro SM, Griffin AS, Hinde CA, West SA (2016) Unpredictable environments lead to the evolution of parental neglect in birds. Nat Commun 7:10985. https://doi.org/10.1038/ncomms10985

Chalfoun AD, Martin TE (2010) Parental investment decisions in response to ambient nest-predation risk versus actual predation on the prior nest. Condor 112:701-710. https://doi.org/10.1525/ cond.2010.090242

Chalfoun AD, Schmidt KA (2012) Adaptive breeding-habitat selection: is it for the birds? Auk 129:589-599. https://doi.org/10.1525/auk. 2012.129.4.589

Collias NE, Collias EC (1985) Nest building and bird behavior. Princeton University Press, Princeton

Coppes J, Kämmerle J-L, Schroth K-E, Braunisch V, Suchant R (2021) Weather conditions explain reproductive success and advancement of the breeding season in Western Capercaillie (Tetrao urogallus). Ibis 163:990-1003. https://doi.org/10.1111/ibi.12924

Danchin E, Wagner RH (1997) The evolution of coloniality: the emergence of new perspectives. Trends Ecol Evol 12:342-347. https:// doi.org/10.1016/S0169-5347(97)01124-5

Davis JN, Todd PM, Bullock S (1999) Environment quality predicts parental provisioning decisions. Proc R Soc Lond B 266:17911797. https://doi.org/10.1098/rspb.1999.0848

Dawson RD, Bortolotti GR (2000) Reproductive success of American kestrels: the role of prey abundance and weather. Condor 102:814-822. https://doi.org/10.1650/0010-5422(2000)102[0814: RSOAKT]2.0.CO;2

Dawson RD, Lawrie CC, O'Brien EL (2005) The importance of microclimate variation in determining size, growth and survival of avian offspring: experimental evidence from a cavity nesting passerine. Oecologia 144:499-507. https://doi.org/10.1007/ s00442-005-0075-7

de Zwaan DR, Drake A, Greenwood JL, Martin K (2020) Timing and intensity of weather events shape nestling development strategies in three Alpine breeding songbirds. Front Ecol Evol 8:570034. https://doi.org/10.3389/fevo.2020.570034

Dickens M, Berridge D, Hartley IR (2008) Biparental care and offspring begging strategies: hungry nestling blue tits move towards the father. Anim Behav 75:167-174. https://doi.org/10.1016/j. anbehav.2007.04.024

Dixson DL, Jones GP, Munday PL, Planes S, Pratchett MS, Thorrold SR (2014) Experimental evaluation of imprinting and the role innate preference plays in habitat selection in a coral reef fish. Oecologia 174:99-107. https://doi.org/10.1007/ s00442-013-2755-Z

Evens R, Beenaerts N, Neyens T, Witters N, Smeets K, Artois T (2018) Author correction: proximity of breeding and foraging areas affects foraging effort of a crepuscular, insectivorous bird. Sci Rep 8:9671. https://doi.org/10.1038/s41598-018-25897-5

Forbes S (2007) Sibling Symbiosis in Nestling Birds. Auk 124:1-10. https://doi.org/10.1642/0004-8038(2007)124[1:Ssinb]2.0.Co;2

Fournier J, Arlettaz R (2001) Food provision to nestlings in the Hoopoe Upupa epops: implications for the conservation of a small endangered population in the Swiss Alps. Ibis 143:2-10. https://doi.org/ 10.1111/j.1474-919X.2001.tb04163.x

França LF, Figueiredo-Paixão VH, Duarte-Silva TA, dos Santos KB (2020) The effects of rainfall and arthropod abundance on breeding season of insectivorous birds, in a semi-arid neotropical environment. Zoologia 37:1-7. https://doi.org/10.3897/zoologia.37. e37716

Geiser S, Arlettaz R, Schaub M (2008) Impact of weather variation on feeding behaviour, nestling growth and brood survival in Wrynecks Jynx torquilla. J Ornithol 149:597-606. https://doi.org/10. 1007/s10336-008-0305-y 
Gibson D, Blomberg EJ, Atamian MT, Sedinger JS (2016) Nesting habitat selection influences nest and early offspring survival in Greater Sage-Grouse. Condor 118:689-702. https://doi.org/10. 1650/condor-16-62.1

Gilbert C, McCafferty D, Le Maho Y, Martrette J-M, Giroud S, Blanc S, Ancel A (2010) One for all and all for one: the energetic benefits of huddling in endotherms. Biol Rev 85:545-569. https://doi. org/10.1111/j.1469-185X.2009.00115.x

Goławski A (2006) Impact of weather on partial loss of nestlings in the Red-backed Shrike Lanius collurio in eastern Poland. Acta Ornithol 41:15-20. https://doi.org/10.3161/000164506777834705

Grieco F (2002) Time constraint on food choice in provisioning blue tits, Parus caeruleus: the relationship between feeding rate and prey size. Anim Behav 64:517-526. https://doi.org/10.1006/ anbe. 2002.3073

Hildebrandt B, Schaub M (2018) The effects of hatching asynchrony on growth and mortality patterns in Eurasian Hoopoe Upupa epops nestlings. Ibis 160:145-157. https://doi.org/10.1111/ibi. 12529

Hoset KS, Espmark Y, Moksnes A, Haugan T, Ingebrigtsen M, Lier M (2004) Effect of ambient temperature on food provisioning and reproductive success in Snow Buntings Plectrophenax nivalis in the high artic. Ardea 92:239-246. http://ardea.nou.nu/ardea show_abstract.php?lang $=$ uk\&nr $=28$

Hudec K, Šlastný K (2005) Upupa epops Linnaeus, 1758 - Dudek chochlatý. In: Hudec K, Šlastný K (eds) Ptáci - Aves: Fauna ČR, Svazek 29/2. Akademie věd České republiky, Praha, pp 1086-1092

Huiting HF, Moraal LG, Griepink FC, Ester A (2006) Biology, control and luring of the cockchafer, Melolontha melolontha: literature report on biology, life cycle and pest incidence, current control possibilities and pheromones. PPO, Lelystad

Jaworski T, Hilszczański J (2014) The effect of temperature and humidity changes on insects development their impact on forest ecosystems in the expected climate change. For Res Pap 74:345-355. https://doi.org/10.2478/frp-2013-0033

Jones J (2001) Habitat selection studies in avian ecology: a critical review. Auk 118:557-562. https://doi.org/10.1093/auk/118.2.557

Jovani R, Tella JL (2004) Age-related environmental sensitivity and weather mediated nestling mortality in white storks Ciconia ciconia. Ecography 27:611-618. https://doi.org/10.1111/j.0906-7590. 2004.03925.x

Kilner RM (2002) The evolution of complex begging displays. In: Wright J, Leonard ML (eds) The evolution of begging. Springer, Dordrecht, pp 87-106

Kölliker M, Richner H (2004) Navigation in a cup: chick positioning in great tit, Parus major, nests. Anim Behav 68:941-948. https:// doi.org/10.1016/j.anbehav.2003.11.019

Krištín A (2001) Family Upupidae (Hoopoe). In: del Hoyo J, Elliott A, Sargatal J (eds) Handbook of the birds of the world, mousebirds to hornbills. Lynx Edicions, Barcelona, pp 396-411

Krištofík J, Mašán P, Šustek Z, Nuhličková S (2013) Arthropods (Acarina, Coleoptera, Siphonaptera) in nests of hoopoe (Upupa epops) in Central Europe. Biologia 68:155-161. https://doi.org/10.2478/ s11756-012-0135-5

Kubík V (1960) Příspěvky k hnízdní bionomii dudka chochlatého [Beiträge zur Fortpflanzungsbionomie des Wiedehopfes (Upupa epops)]. Folia Zool 9:97-110. https://kramerius.lib.cas.cz/view/ uuid:2cea2cc3-56d6-11e1-1726-001143e3f55c?page=uuid:2cea2 d2a-56d6-11e1-1726-001143e3f55c

Larson ER, Eastwood JR, Buchanan KL, Bennett ATD, Berg ML (2015) How does nest-box temperature affect nestling growth rate and breeding success in a parrot? Emu 115:247-255. https://doi. org/10.1071/MU14081
Lima SL (2009) Predators and the breeding bird: behavioral and reproductive flexibility under the risk of predation. Biol Rev 84:485513. https://doi.org/10.1111/j.1469-185X.2009.00085.x

Maresh Nelson SB, Coon JJ, Miller JR (2020) Do habitat preferences improve fitness? Context-specific adaptive habitat selection by a grassland songbird. Oecologia 193:15-26. https://doi.org/10. 1007/s00442-020-04626-8

Marques PAM, Leonard ML, Horn AG, Contasti A (2011) How nestling tree swallows (Tachycineta bicolor) integrate their responses to hunger and signalling by nestmates. Ethology 117:163-170. https://doi.org/10.1111/j.1439-0310.2010.01859.x

Martín-Vivaldi M, Palomino JJ, Soler M, Soler JJ (1999) Determinants of reproductive success in the Hoopoe Upupa epops, a hole-nesting non-passerine bird with asynchronous hatching. Bird Study 46:205-216. https://doi.org/10.1080/00063659909461132

Maziarz M, Wesołowski T (2013) Microclimate of tree cavities used by Great Tits (Parus major) in a primeval forest. Avian Biol Res 6:47-56. https://doi.org/10.3184/175815513x13611994806259

Mock DW, Parker GA (1997) The evolution of sibling rivalry. Oxford University Press, Oxford

Morris DW (2003) Toward an ecological synthesis: a case for habitat selection. Oecologia 136:1-13. https://doi.org/10.1007/ s00442-003-1241-4

Morris DW (2011) Adaptation and habitat selection in the eco-evolutionary process. Proc R Soc Lond B 278:2401-2411. https://doi. org/10.1098/rspb.2011.0604

Naef-Daenzer B (2000) Patch time allocation and patch sampling by foraging great and blue tits. Anim Behav 59:989-999. https://doi. org/10.1006/anbe.1999.1380

Nelder JA, Wedderburn RW (1972) Generalized linear models. J Roy Stat Soc A 135:370-384. https://doi.org/10.2307/2344614

Nielsen SE, Shafer ABA, Boyce MS, Stenhouse GB (2013) Does learning or instinct shape habitat selection? PLoS ONE 8:e53721. https://doi.org/10.1371/journal.pone.0053721

Nuhlíčková S, Krištín A, Degma P, Hoi H (2016) Variability in nestling diet of European hoopoes: annual and sampling effect. Folia Zool 65:189-199. https://doi.org/10.25225/fozo.v65.i3.a3.2016

Nuhlíčková S, Svetlík J, Eckenfellner M, Knauer F, Hoi H (2021) Interaction between nestling behaviour and nest-space use. Ethol Ecol Evol 33:496-514. https://doi.org/10.1080/03949370.2020. 1858173

Öberg M, Arlt D, Pärt T, Laugen AT, Eggers S, Low M (2015) Rainfall during parental care reduces reproductive and survival components of fitness in a passerine bird. Ecol Evol 5:345-356. https:// doi.org/10.1002/ece3.1345

Orians GH, Pearson NE (1979) On the theory of central place foraging. In: Horn DJ, Mitchell RD, Stairs GR (eds) Analysis of ecological systems. Ohio State University Press, Ohio, pp 154-177

Ostreiher R (2001) The importance of nestling location for obtaining food in open cup-nests. Behav Ecol Sociobiol 49:340-347. https:// doi.org/10.1007/s002650000308

Parker GA, Royle NJ, Hartley IR (2002) Begging scrambles with unequal chicks: interactions between need and competitive ability. Ecol Lett 5:206-215. https://doi.org/10.1046/j.1461-0248.2002. 00301.x

Piper WH (2011) Making habitat selection more "familiar": a review. Behav Ecol Sociobiol 65:1329-1351. https://doi.org/10.1007/ s00265-011-1195-1

Pipoly I, Bókony V, Seress G, Szabó K, Liker A (2013) Effects of extreme weather on reproductive success in a temperate-breeding songbird. PLoS ONE 8:e80033. https://doi.org/10.1371/journal. pone. 0080033

Porkert J, Špinka M (2006) Begging in common redstart nestlings: scramble competition or signalling of need? Ethology 112:398410. https://doi.org/10.1111/j.1439-0310.2005.01177.x 
Porter CK, Akcali CK (2018) An alternative to adaptation by sexual selection: habitat choice. Trends Ecol Evol 33:576-581. https:// doi.org/10.1016/j.tree.2018.05.004

R Core Team (2018) R: a language and environment for statistical computing. R Foundation for Statistical Computing, Vienna, Austria. http://www.R-project.org/

Radford AN, McCleery RH, Woodburn RJW, Morecroft MD (2001) Activity patterns of parent Great Tits Parus major feeding their young during rainfall. Bird Study 48:214-220. https://doi.org/10. 1080/00063650109461220

Reichert BE, Cattau CE, Fletcher RJ Jr, Kendall WL, Kitchens WM (2012) Extreme weather and experience influence reproduction in an endangered bird. Ecology 93:2580-2589. https://doi.org/ 10.1890/12-0233.1

Rhodes B, O'Donnell C, Jamieson I (2009) Microclimate of natural cavity nests and its implications for a threatened secondary-cavitynesting passerine of New Zealand, the South Island Saddleback. Condor 111:462-469. https://doi.org/10.1525/cond.2009.080030

Rivrud IM, Loe LE, Mysterud A (2010) How does local weather predict red deer home range size at different temporal scales? J Anim Ecol 79:1280-1295. https://doi.org/10.1111/j.1365-2656. 2010.01731.x

Roulin A, Dreiss A (2012) Sibling competition and cooperation over parental care. In: Royle NJ, Smiseth PR, Kölliker M (eds) The evolution of parental care. Oxford University Press, Oxford, pp 133-149

Royle NJ, Hartley IR, Parker GA (2002) Begging for control: when are offspring solicitation behaviour honest? Trends Ecol Evol 17:434-440. https://doi.org/10.1016/S0169-5347(02)02565-X

Ryser S, Guillod N, Bottini C, Arlettaz R, Jacot A (2016) Sex-specific food provisioning patterns by parents in the asynchronously hatching European hoopoe. Anim Behav 117:15-20. https://doi.org/10. 1016/j.anbehav.2016.04.015

Sauve D, Friesen VL, Charmantier A (2021) The effects of weather on avian growth and implications for adaptation to climate change. Front Ecol Evol 9:569741. https://doi.org/10.3389/fevo.2021

Schwemmer P, Güpner F, Adler S, Klingbeil K, Garthe S (2016) Modelling small-scale foraging habitat use in breeding Eurasian oystercatchers (Haematopus ostralegus) in relation to prey distribution and environmental predictors. Ecol Model 320:322-333. https://doi.org/10.1016/j.ecolmodel.2015.10.023

Smith MG, Dickinson JL, Rush A, Wade AL, Yang D-S (2017) Western bluebird parents preferentially feed hungrier nestlings in a design that balances location in the nest. Behav Ecol Sociobiol 71:58. https://doi.org/10.1007/s00265-017-2287-3
Tagmann-Ioset A, Schaub M, Reichlin TS, Weisshaupt N, Arlettaz $R$ (2012) Bare ground as a crucial habitat feature for a rare terrestrially foraging farmland bird of Central Europe. Acta Oecol 39:25-32. https://doi.org/10.1016/j.actao.2011.11.003

Tanner M, Kölliker M, Richner H (2007) Parental influence on sibling rivalry in great tit, Parus major, nests. Anim Behav 74:977-983. https://doi.org/10.1016/j.anbehav.2006.11.034

Tobolka M, Zolnierowicz KM, Reeve NF (2015) The effect of extreme weather events on breeding parameters of the White Stork Ciconia ciconia. Bird Study 62:377-385. https://doi.org/10.1080/00063 657.2015.1058745

Tökölyi J, McNamara JM, Houston AI, Barta Z (2012) Timing of avian reproduction in unpredictable environments. Evol Ecol 26:25-42. https://doi.org/10.1007/s10682-011-9496-4

Tremblay I, Thomas DW, Blondel J, Perret P, Lambrechts MM (2005) The effect of habitat quality on foraging patterns, provisioning rate and nestling growth in Corsican Blue Tits Parus caeruleus. Ibis 147:17-24. https://doi.org/10.1111/j.1474-919x.2004.00312.x

Uboni A, Smith DW, Stahler DR, Vucetich JA (2017) Selecting habitat to what purpose? The advantage of exploring the habitat-fitness relationship. Ecosphere 8:e01705. https://doi.org/10.1002/ecs2. 1705

Wann GT, Aldridge CL, Braun CE (2016) Effects of seasonal weather on breeding phenology and reproductive success of Alpine ptarmigan in Colorado. PLoS ONE 11:e0158913. https://doi.org/10. 1371/journal.pone. 0158913

Wesołowski T (2002) Anti-predator adaptations in nesting Marsh Tits Parus palustris: the role of nest-site security. Ibis 144:593-601. https://doi.org/10.1046/j.1474-919X.2002.00087.x

Wesołowski T (2017) Failed predator attacks: a direct test of security of tree cavities used by nesting Marsh Tits (Poecile palustris). Auk 134:802-810. https://doi.org/10.1642/Auk-17-51.1

Wesołowski T, Maziarz M (2012) Dark tree cavities - a challenge for hole nesting birds? J Avian Biol 43:454-460. https://doi.org/10. 1111/j.1600-048X.2012.05704.X

Wiebe KL (2001) Microclimate of tree cavity nests: Is it important for reproductive success in northern flickers? Auk 118:412-421. https://doi.org/10.1642/0004-8038(2001)118[0412:Motcni]2.0. $\mathrm{Co} ; 2$

Publisher's note Springer Nature remains neutral with regard to jurisdictional claims in published maps and institutional affiliations.

\section{Authors and Affiliations}

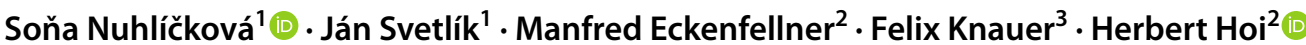

1 Department of Ecology, Faculty of Natural Sciences, Comenius University, Mlynská dolina, 84215 Bratislava, 4, Slovakia

2 Department of Interdisciplinary Life Sciences, Konrad Lorenz Institute of Ethology, University of Veterinary Medicine, Savoyenstraße 1a, 1160 Vienna, Austria
3 Conservation Medicine, Department of Interdisciplinary Life Sciences, Research Institute of Wildlife Ecology, University of Veterinary Medicine, Savoyenstraße 1a, 1160 Vienna, Austria 